SHS Web of Conferences 2, 00032 (2012)

DOI: $10.1051 /$ shsconf $/ 20120200032$

(C) Owned by the authors, published by EDP Sciences, 2012

\title{
Internet social networks as important agents of social inclusion for contemporary children and youth
}

\author{
L. Stasova and J. Khynova \\ University of Hradec Králové, Czech Republic
}

\begin{abstract}
The article shows that the use of social networks is a very powerful mean and often the way of socialization and social inclusion of contemporary children and youth. Direct social communication is often substituted by communication through the modern media, which takes places in the cyber space and has a great importance for experience and socialization of current generations. This article is trying to point out that the use of internet social networks is an important component of children's and youth's subculture. Potential absence in the world of internet social networks can bring individuals to the marginal position among their peer group. On the basis of the survey made among Czech children and youngsters, from 11 to 19 years, we can find out how important the use of internet social networks for the Czech contemporary young people is. Activities connected with the internet social networks create an important part of leisure time activities for the interviewed respondents. For them it is very considerable to be the part of some internet social community. Moreover, virtual communication helps respondents to keep in touch with their peers and increase their social status in the community. They can also experiment with different identities and find the best way of communication with others.
\end{abstract}

Key words: socialization, social inclusion, internet social networks, children, youth

The life in the information society cannot be imagined without the powerful influence of media technologies. Contemporary children and young people are the part of generation that grow up in information society so using of modern communication technologies belongs to them from their babyhood. Czech researchers Sak and Saková (2004) point out that transformation of living area and its component parts label contemporary adolescents significantly. Young generation's social field is changed by mass media in the most radical way. The share of virtual reality increases in life of the young generation while the share of natural reality decreases. Some authors (e.g., Prensky, 2001; Palfrey, 2008) use the term "digital natives" for those people who move in the environment equipped with modern computer technologies without any problem. A "digital native" is a person for whom digital technologies already exist when he or she was born, and hence this person has grown up with digital technology such as computers, the Internet, mobile phones and MP3s.

Today's generations of children and adolescents are absolutely naturally familiar with modern information and communication means and they cope with them spontaneously and without troubles. Communication rapidity and access to the large amount of information are positives which new living environment provides to children. On the contrary virtualization of human relations and digitalization of the needs belong to the weak points of this development. Through digitalization of the human being and "through interaction in cyberspace, those component of a man's personality that are functional, active and needful in this interaction are developed" (Sak, Saková, 2004). That is why the young generation communicates and lives its social relations in another way than the previous generations.

The life of contemporary society exists more and more in two spheres, real and virtual ones. Today's peer community is often based not only on the natural basis of the face-to-face communication and personal relations but it can be also created through the virtual communication and internet social networks. "Face-to-face solidarity was replaced by more abstract and impersonal expectations and

This is an Open Access article distributed under the terms of the Creative Commons Attribution License 2.0, which permits unrestricted use, distribution, and reproduction in any medium, provided the original work is properly cited. 


\section{SHS Web of Conferences}

norms of behaviour" (Phillips, 2008). This could be a good reason for discussion about social inclusion of the young generation in the "virtual society" based on the internet social networks. The concept of social inclusion (e.g., Wessels, Miedema, 2006) identifies three dimensions of inclusion - starting with individual (biographical) level, continues with level of neighbourhood, which is group or network that is called "social" or "life" world and finally the societal or structural level. Loader (1998) explains in his study how the social inequality is reproduced in the same way in the cyberspace as in the real society. He demonstrates that "for the vast majority of the world's population, the possibility of constructing virtual identities is entirely dependent upon their material situation. Clearly most people are not free to choose but instead are subject to a variety of social and economic conditions which act to structure and articulate their opportunities for action" (Loader, 1998). In this text, there is emphasised the level of social inclusion on the level of peer group, i.e. on the level of "social world" of the person.

\section{Materials and methods}

The area of the internet social networks application and their importance in the life of Czech children and youth has not been mapped out too well so far. Regular surveys of these issues are realized by the company Microsoft; the other interesting projects are exercised by the Centre of Prevention of Hazard Virtual Communication. In this text we use data from our project of specific research realized under the name "Construction of Identity and Contemporary Adolescent's Identity Experiments within the Framework of Social Networks" at the Faculty of Education of University of Hradec Králové in 2010. The research topic asks questions connected to the role of internet social networks in social lives of the contemporary young people and with the consequences of using of the internet social networks in individual identity's formation. In this context we can also discuss problems of social inclusion of the young generation in the context of media use.

This research survey was running in the first half of the year 2010 in the form of questionnaire among respondents from 11 to 19 years old attending basic and secondary schools. It was casual selection and it was made in the Hradec Králové Region. Among secondary schools there were high schools, secondary vocational schools and secondary training colleges as well. In our questionnaire survey 708 respondents participated -312 girls and 396 boys. These respondents filled the questionnaire containing 32 items; partly formed with closed questions, partly with open questions with possibility to answer them without restraints.

\section{Results}

In the first part of our survey we were trying to find out which particular internet social networks are used by young people, how often, why and how. We also asked the question how intensive the circle of internet friends of the young respondents is and how it is possible to evaluate it in comparison with the circle of friends from the immediate social vicinity of person. We presupposed that use of the internet social networks is a part of subculture of the contemporary young generation. That is why motives for using them are not only accessibility and attractiveness but also the pressure of a peer group which demands this way of communication.

Our data displayed that internet social networks have really marked interest. $98 \%$ of respondents answered positively to the question if they sometimes use internet social networks. This matter of fact confirmed the marked interest and considerable socialization provided by internet social environment to the young generation. The most often used social networks are YouTube and Facebook, which could be labelled as well-known. On the other hand, there is the second group where are less wide-spread networks which are used by the young generation as well. We speak mainly about MySpace and Twitter. Our survey results fully correspond to Krejčí and Kopecký (2009) findings who pointed in their survey that $99,5 \%$ children know at least one social network. They also found that the most used social networks in the Czech Republic are YouTube and Facebook. 
Int. Conf. SOCIETY. HEALTH. WELFARE; Congr. of Rehabilitation Doctors of Latvia

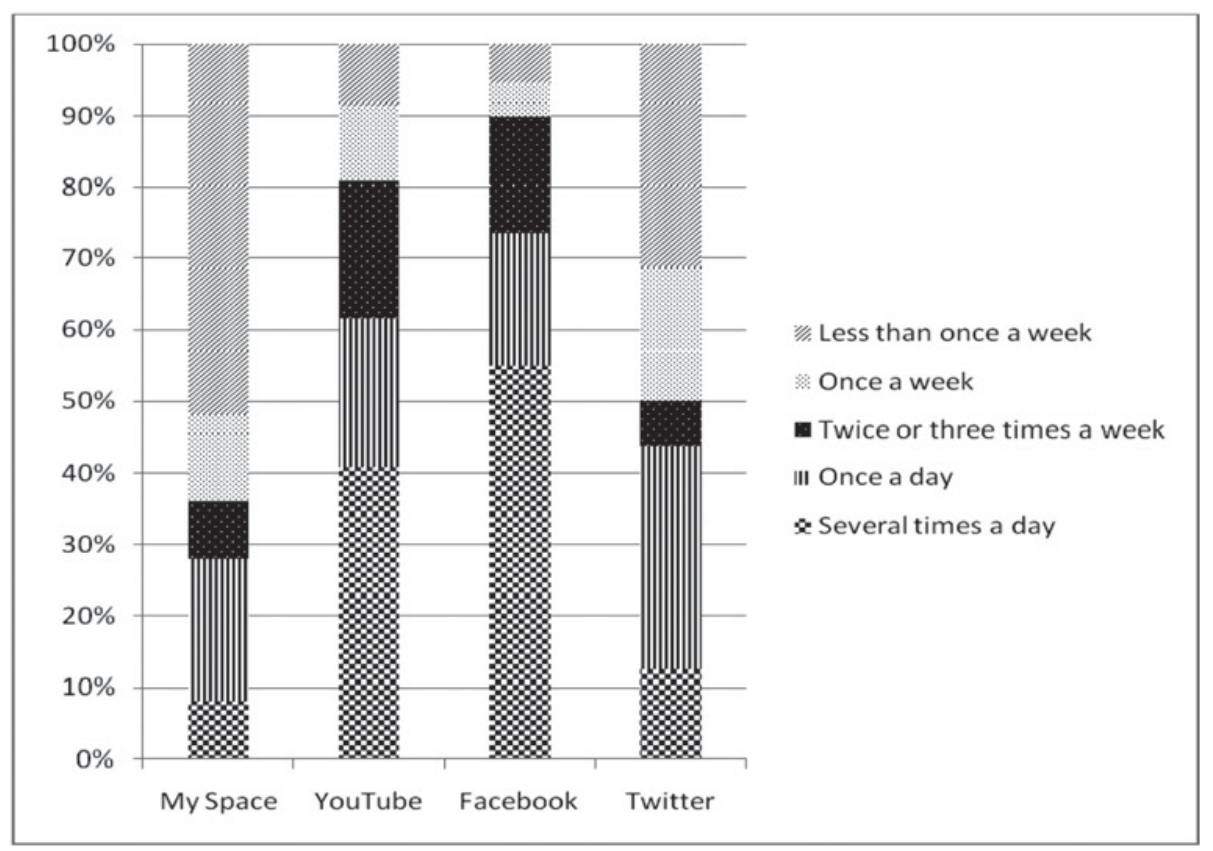

Figure 1. Selected social networks use frequency.

Boys used social networks approximately as often as girls; however, girls used Facebook a little bit more often than boys. Facebook and YouTube are used by more than $50 \%$ of respondents because they have opened an account there. That is why we can say that the internet social networks are daily friends for more than half of the contemporary children. It was proved that $80 \%$ of respondents use internet social networks regularly every day. Generally we can assume that the use of internet social networks is the real social activity needed for belonging to the society and social groups.

Why are the internet social networks so often used? Our data showed that the main reasons are "the need to be in contact with somebody", "there are all my friends" and "boredom" (Table 1). The different power of reasons for the usage of networks comes out between genders. While the important stimuli of using for girls are usually the facts they want to be in contact with somebody and that there are all their friends there; the important role for boys is mainly boredom. The other factors are for respondents much less important. Therefore we can consider that the use of internet social networks fills primarily the need of social communication, even though the need of satisfying a peer group demands is not irrelevant as well, mainly for girls. The influence of boredom is also an interesting factor. The need of knowing new people is obvious in the period of adolescence and it enables them to wide their social field.

In regard to the research results the main profit of the usage of the internet social networks for young people is "contact with the others" and "knowledge what happens". In this sense the matter of question is purely social reasons. Mass expansion of social networks and possibility of social inclusion are closely linked as well as affecting each other. Because the majority of contemporary young people are members of the social networks we can say that basically every event or activity is planned there, every problem of interest is discussed there because the possibility of providing information to a huge amount of people in one time is much easier than contacting them one by one. That is why people who are not members of the social networks can be easily "forgotten". They do not know about planned events, they can not participate in discussions over actual problems. That leads to their slow separation from the group of friends and peers. In this age, friendships are supported by common experiences and mutual communication which is something social network can help with. 


\section{SHS Web of Conferences}

Table 1. Reasons of internet social networks use with regard to gender.

\begin{tabular}{|l|c|c|c|}
\hline Reasons of using ISN/ Gender & Boys & Girls & Total \\
\hline Need to be in contact with somebody & 30,0 & 37,3 & 33,1 \\
\hline All my friends are there & 16,7 & 24,0 & 19,9 \\
\hline Boredom & 25,5 & 11,5 & 19,2 \\
\hline I want to meet new people & 11,0 & 11,0 & 11,0 \\
\hline I want to have information about people & 7,2 & 9,2 & 8,1 \\
\hline I want to be "in" & 2,0 & 0,7 & 1,6 \\
\hline Anything else & 6,8 & 6,3 & 7,1 \\
\hline Total & 100,0 & 100,0 & 100,0 \\
\hline
\end{tabular}

The most experienced loss in connection with the use of internet social networks is waste of time $(75,4 \%)$. More than one quarter of respondents also think that in this way they loose face-to-face contacts with people from their environment. Also $21 \%$ of respondents are aware of loosing their privacy what they accept negatively. Bigger differences in answering those questions in regard to gender are not found. It appears that young people are able to review positive and negative sides of social networks use. They realize themselves pretty much that being a member of social community is not just something modern and extraordinary but more like something common and necessary. It also documents the fact that most of respondents assess social networks as something that take their time and privacy but the fear of exclusion from the "center stage" will not allow them to cancel their membership there. This effect could be compared to the effect of drugs, because user himself or herself is aware of the negatives but the fear of loss of the "positives" is stronger.

How can we compare the real social contacts of the respondents with the contacts on internet social networks? That is why we try to examine the fact if in its immediate vicinity the contemporary young generation finds people considered to be friends. $5 \%$ of our young respondents admit that in their real environment they do not have any friend, 3/4 have more such friends, and $20 \%$ have one friend. $69 \%$ think that they have many friends; on the contrary $28 \%$ think the number is lower. We can speculate what the contemporary young generation considers to be friendship and how the number of friends is influenced by internet social networks.

Those respondents having only one or none friend assess their situation that they have rather few friends and in their free time they mention watching television, reading and the use of Internet more often than others but they do not talk about the social networks use. In the internet environment there can also be seen various activities that we can differ as social and dissocial. There is the lower number of introvert individuals with the minor impact of their social fields. They also differ in using social networks. They share photos with their friends less commonly than individuals with more friends and they also use networks to communicate with friends not as often. Otherwise they play online games on social networks and they watch videos there.

The amount of contacts that young people have in social networks vary among different ranges, from units (fewer than $4 \%$ of social networks users have less than 10 contacts) to thousands (the maximum number mentioned was 2080). Answer to the question "How many of these contacts do you consider to be your friends?" also showed an interesting dispersion, from units to hundreds and in two cases to thousands. The big extent appears during finding out how many of these friends from social networks respondents know personally. The reports are shown in the Table 2.

From the general point of view, young people use internet social networks mainly to meet, gain friends and to maintain contacts (Table 3). The most common way of the use of the internet social networks is to mix in and to maintain friendships (64\%). In these ways the young generation seek via modern technologies similar and close individuals with who they want to enter social contacts. The other frequent ways of using it are to meet people, to maintain contacts and communication; differently 
Int. Conf. SOCIETY. HEALTH. WELFARE; Congr. of Rehabilitation Doctors of Latvia

Table 2. Number of contacts and friends at social networks (in percentage of respondents that mentioned the given number).

\begin{tabular}{|l|c|c|c|c|}
\hline Question/ Number of contacts (friends) & $\mathbf{1 - 9}$ & $\mathbf{1 0 - 9 9}$ & $\mathbf{1 0 0}$ and more & Total \\
\hline How many contacts do you have on your account? & 2,5 & 28,8 & $\mathbf{6 8 , 7}$ & 100,0 \\
\hline $\begin{array}{l}\text { How many of these contacts do you consider to be } \\
\text { your friends? }\end{array}$ & 10,1 & $\mathbf{5 7 , 7}$ & 32,2 & 100,0 \\
\hline $\begin{array}{l}\text { How many of these on-line friends do you } \\
\text { know personally? }\end{array}$ & 5,1 & 46,8 & $\mathbf{4 8 , 1}$ & 100,0 \\
\hline
\end{tabular}

Table 3. Common ways of internet social networks use.

\begin{tabular}{|l|c|}
\hline Way of social networks use & Number of respondents (in \%) \\
\hline Friends & $\mathbf{6 4 , 4}$ \\
\hline Meeting people & 29,5 \\
\hline Maintaining of existing contacts & 28,7 \\
\hline Photos & 27,3 \\
\hline Games & 26,8 \\
\hline Videos & 25,8 \\
\hline Communication & 25,0 \\
\hline Getting feedback of oneself & 16,7 \\
\hline Self-presentation & 6,1 \\
\hline Another way & 3,0 \\
\hline
\end{tabular}

orientated group of activities at networks is sharing videos, photos and playing games. The interesting matter of fact is finding out that the use of social networks to play online games and sharing videos is much often typical for boys; otherwise questioned girls prefer sharing photos. In this way it is possible to observe virtual space formation of internet social networks. The basic parts of this space are relations among people and sharing information about each other. The question remains to which extent the young generation takes the connected contacts and shared information as a part of the real life or of its virtual dimension. Games are also often mentioned as the interesting aspect of the virtual reality. Data proved that using games at social networks is mainly domain of younger adolescents, it means to the age of thirteen.

Respondent's security at network showed that almost half of them are visible only for friends (52\%), $11 \%$ only for selected friends and just $9 \%$ for friends' friends. Quite alarming fact is that almost the quarter of respondents is visible for everybody. At networks $15,3 \%$ of respondents accept everybody who asks for it and 11,4\% accept almost everybody. 69\% of respondents accept only friends. It shows that it is clear that almost quarter of respondents is willing to accept unknown people as well. The possibility of abuse information at social networks is quite big. In our survey differences among girls and boys and among single age categories in terms of security at networks, searching friends and accepting friends, have not been confirmed. In this sense we can say that all groups of adolescents using social networks are threatened with the comparable risk.

\section{Conclusions}

Our survey showed that internet social networks are used by the major portion of interviewed children and youth. Activities connected with the internet social networks are important parts of spending free time of our respondents. For them it is very considerable to be a part of some internet social community. Social networks bring a sense of big family, community, where everyone can communicate with 


\section{SHS Web of Conferences}

everyone and all together share experiences. Users feel that they are belonging somewhere, responding to someone and someone responds to them. Moreover, the virtual communication helps the respondents to keep in touch with their peers and increase their social status in the community. Every young person needs to feel that he or she is accepted by someone. So through a social network they can test on what people react the most and on what they do not react at all, so he or she can edit his or her behavior and ideas to make it to be "liked" by as many people as possible. In this way they are testing new possible roles.

Young people can also experiment with their identities and find the ways of better communication with others and of simpler inclusion to the group. For individuals who fail in face-to-face relation this form of communication can be beneficial because through a network is easier to establish contacts and find out on what are peers responding positively and on what negatively. Our investigation has also showed that people who can not and do not want to use internet social networks can be excluded from their everyday groups by the peer public opinion. Access to modern communication media and being a part of some internet social network are seen as important factors of the successful socialization, social inclusion and social learning of current young generations.

Therefore we can assume that internet social networks as virtual communities play important role in the lives of contemporary children and youth. Our respondents often expressed this fact by the statement "Who is not on Facebook does not exist." The natural peer groups (schoolmates, friends from the neighbourhood) share their lives not only through the face-to-face communication but parallelly in the virtual world. Furthermore, the balance between inclusion and exclusion in the cyber world is an interesting issue for the next research. The above mentioned problems can turn us to the further discussion about the access of young people to the Internet, about spending their leisure time, about the media education, about values and culture in information society, as well as about justice and protection of children and youth against social networks abuse.

\section{References}

[1] Gross, E.F. (2004) Adolescent Internet use: what we expected, what teens report. Journal of Applied Developmental Psychology, 25.

[2] Krejčí, V., Kopecký, K. (2009) Kyberšikana u českých dětí - závěry z výzkumného šetření projektu E-Bezpečí a Centra PRVOK (záŕí - listopad 2009). [CyberBullying at (of) Czech Children - the research survey results from the project E-Safety and Center PRVOK]. (September-November 2009). http://prvok.upol.cz/index.php/vyzkum

[3] Loader, B.D. (Ed.) (1998) Cyberspace Divide. Equality, Agency and Policy in the Information Society. Routledge.

[4] Morahan-Martin, J., Schumacher, P. (2003) Loneliness and social use of the Internet. Computers in Human Behavior, 19.

[5] Palfrey, J., Gasser, U. (2008) Born Digital. New York: Basic Books.

[6] Phillips, D. (2008) Social inclusion, social exclusion and social cohesion: tensions in a postindustrial world. In The Hong Kong Journal of Social Work. Vol. 42 (1/2).

[7] Prensky, M. (2001) Digital Natives. Digital Immigrants. In On the Horizon. NCB University Press. Vol. 9 (5).

[8] Sak, P., Saková, K. (2004) Mládež na křžovatce. [Youth on the Crossroad] $1^{\text {st }}$ edition. Prague: Svoboda Servis.

[9] Wessels, B., Miedema, S. (2006) Towards understanding situations of social exclusion. In Welfare Policy from Below: Struggles Against Social Exclusion in Europe. Aldeshot, Ashgate. 